\title{
Uso de embalagem ativa na inibição do escurecimento enzimático de maçãs
}

\section{Active packaging use to inhibit enzymatic browning of apples}

\author{
Talita Moreira de Oliveira ${ }^{1}$; Nilda de Fátima Ferreira Soares ${ }^{2 *}$; \\ Cláudia Denise de Paula ${ }^{3}$; Giulliano Amaral Viana ${ }^{4}$
}

\section{Resumo}

O escurecimento enzimático é um dos fatores mais limitantes da vida de prateleira de frutas e vegetais. $\mathrm{O}$ objetivo desse estudo foi avaliar o efeito do uso de embalagem ativa incorporada com agentes antioxidantes na inibição do escurecimento enzimático de maçãs. Os filmes foram produzidos a base de polímero celulósico e incorporados com sulfito e cisteína para recobrimento de maçãs divididas ao meio. Foi avaliada a inibição do escurecimento através da atividade da polifenoloxidase e pela análise de cor (sistema CIE Lab). Baixas concentrações de sulfito (1\%) mostraram-se eficientes na inibição do escurecimento das maçãs e altas concentrações de cisteína (15\%) foram necessárias para a obtenção do mesmo resultado. Os tratamentos tanto com sulfito quanto com cisteína, comparados com os tratamentos controle, proporcionaram maior brilho às maçãs e menor escurecimento. $\mathrm{O}$ teor de sulfito liberado para a maçã foi menor que o permitido pela legislação, diminuindo assim, os níveis de aditivos que serão ingeridos pelo consumidor. Comprovou-se a eficiência das embalagens ativas que proporcionaram conservação do produto, inibindo o desenvolvimento de escurecimento.

Palavras-chave: Embalagem ativa, polifenoloxidase, frutas, escurecimento enzimático

\begin{abstract}
The enzymatic browning is the most limiting factor of fruits and vegetables shelf-life. The objective of this study was to evaluate the effect of an active packaging incorporated with anti-oxidant agents to inhibit apple's enzymatic browning. Cellulosic films were incorporated with cysteine and sulphite and used to cover apples divided in halves. Browning inhibition was measured by polyphenoloxidase activity and colour analysis (CIE Lab colour system). Low concentration of sulphite (1\%) showed efficient browning inhibition and higher concentration of cysteine $(15 \%)$ was necessary to reach the same results. Treatments containing cysteine and sulphite resulted in brighter apples and less browning compared with control. The quantity of sulphite released to apples was lower than the limit allowed by legislation, decreasing, in this way, the levels of additives ingested by the consumer. In this study, the effectiveness of active packaging in providing product conservation was confirmed by the inhibition of browning in apples.
\end{abstract}

Key words: Active packaging, polyphenoloxidase, fruits

1 Mestre em Ciência e Tecnologia de Alimentos UFV. moreiratalita@yahoo.com.br

2 Professora do depto de Tecnologia de Alimentos, Universidade Federal de Viçosa, 36570-000 - Viçosa-MG.nfsoares@ufv.br

3 Professora da Universidad de Córdoba, Monteria, Colombia. cdenise@sinu.unicordoba.edu.co

4 Mestre em Ciência e Tecnologia de Alimentos UFV. amaralviana@yahoo.com.br

* Autor para correspondência 


\section{Introdução}

Os atributos de qualidade de um alimento incluem dentre outros a cor, textura, flavor e valor nutricional. Frutas e hortaliças, além de altamente nutritivas, são bastante atrativas devido à variedade de pigmentos que contêm e, assim, a cor é um critério importante na decisão de compra pelo consumidor. A preservação dos pigmentos responsáveis por essa característica é de fundamental importância para a qualidade desses produtos. As mudanças de cor em frutas e hortaliças possuem diferentes origens, podendo ser influenciadas pela presença de pigmentos naturais, como clorofilas, carotenóides e antocianinas ou por pigmentos formados em reações enzimáticas e não enzimáticas (MARSHALL; KIM; WEI, 2000).

$\mathrm{O}$ escurecimento enzimático ocorre devido à presença da enzima polifenoloxidase (PPO), um termo genérico utilizado para designar um grupo de enzimas que catalisam a oxidação de compostos fenólicos, produzindo pigmentos escuros em cortes ou superfícies danificadas de frutas e hortaliças (SIMÕES, 2004). O escurecimento enzimático não ocorre em células intactas, pois os compostos fenólicos que se encontram nos vacúolos celulares ficam separados da PPO que está presente nos plastos. Quando o tecido é danificado pelo corte, a enzima entra em contato com seu substrato e a formação de pigmentos escuros ocorre (MARSHALL; KIM; WEI, 2000; MARTINEZ; WHITAKER, 1995), favorecido pela exposição ao oxigênio.

A PPO catalisa inicialmente a hidroxilação de monofenóis para $o$-difenóis e depois a dehidrogenação de $o$-difenóis para $o$-quinonas (CRUMIÉRE, 2000). As $o$-quinonas são altamente reativas e rapidamente oxidam e polimerizam, resultando na formação de pigmentos escuros denominados melaninas. Além de descoloração, podem aparecer sabores indesejáveis e diminuição de valor nutricional (GARCIA; BARRET, 2002; ARAÚJO, 2001; MARSHALL; KIM; WEI, 2000).

A maçã é uma fruta bem aceita pela população, porém, bastante susceptível à deterioração causada pelo escurecimento enzimático, tornando-se inadequada para o consumo devido à formação de coloração escura. Em maçãs, os substratos para a PPO são a catequina, a epicatequina e o ácido clorogênico. As catequinas se oxidam mais rapidamente do que o ácido clorogênico, porém, como a concentração do ácido é muito maior do que a das catequinas, o seu efeito no escurecimento é mais pronunciado (ROCHA; MORAIS, 2001; GOUPY et al., 1995).

O controle do escurecimento enzimático pode ser feito através de métodos físicos e/ou químicos. Métodos físicos incluem redução de temperatura ou inativação térmica da enzima, proteção do produto contra oxigênio, desidratação, uso de atmosfera modificada, embalagens ativas e outros. Métodos químicos envolvem o uso de compostos que inibem a ação da enzima. A inativação enzimática da PPO por aquecimento é possível aplicando temperaturas superiores a $50^{\circ} \mathrm{C}$, porém isso pode produzir cores e flavors indesejáveis, como também mudanças na textura (MARTINEZ; WHITAKER, 1995). A aplicação de temperaturas baixas apenas reduz a atividade enzimática, porém não provoca inativação. Alguns químicos já testados com eficácia comprovada na inibição da PPO podem ser prejudiciais ao produto e ao consumidor, trazendo riscos de toxicologia e efeitos sensoriais ao produto (GARCIA; BARRETT, 2002; MARSHALL; KIM; WEI, 2000).

O uso de compostos redutores, como o sulfito e a cisteína, são bastantes efetivos no controle do escurecimento enzimático. Eles previnem o escurecimento através da redução das $o$-quinonas para $o$-difenóis, que são compostos menos escuros; ou pela complexação com produtos da reação enzimática formando compostos de coloração mais clara e estáveis ou ainda pela inativação irreversível da PPO (CRUMIÉRE, 2000; LOZANO-DEGONZALEZ et al., 1993).

Os sulfitos, provavelmente, considerados os mais efetivos e os mais baratos agentes antiescurecimento, 
porém estão sujeitos a restrições devido aos efeitos adversos que podem causar à saúde, como alergias e ao produto, como perda de textura, desenvolvimento de sabor desagradável e perda de vitamina $B_{1}$ (ROUX et al., 2003). A sua forma de ação não é completamente entendida. Alguns autores sugerem que ocorre uma inibição competitiva do sulfito sobre a enzima, por se ligar a um grupo sulfidril em um sítio ativo da enzima (BILLAUD et al., 2003). Outros sugerem que a inibição é devido à reação de sulfito com quinonas, resultando na formação de sulfoquinonas, o que inibe irreversivelmente a PPO, causando sua inativação (MARSHALL; KIM; WEI, 2000). De acordo com The Joint Expert Committee on Food Additives (JECFA), a Organização Mundial da Saúde (WHO) e Food and Agriculture Organization (FAO), a ingestão diária máxima recomendada é de $0,7 \mathrm{mg}$ de dióxido de enxofre por quilo de peso corpóreo (MARSHALL; KIM; WEI, 2000). No Brasil, é permitido o máximo de $0,03 \mathrm{~g} \mathrm{SO}_{2} / 100 \mathrm{~g}$ de produto (BRASIL, 2005).

A cisteína, um tiól, conhecido como um efetivo inibidor do escurecimento enzimático, porém o seu mecanismo de ação sobre a PPO não é completamente elucidado. Existem duas hipóteses; uma de que a inibição resulta da formação de complexos conjugados com $o$-quinonas que são mais estáveis ou devido à redução de $o$-quinonas para seus precursores fenólicos e outra devido à ligação de grupos SH da cisteína com o cobre no sítio ativo da enzima, resultando em sua inibição diretamente (MARSHALL; KIM; WEI, 2000; ROBERT et al., 1996; FRIEDMAN, 1996). Essa última hipótese foi confirmada por Ding et al. (2002), que relataram uma forte afinidade entre grupos $\mathrm{SH}$ da cisteína e o cobre. Vários estudos têm demonstrado a sua eficiência na inibição de PPO em suco de maçã (IYIDOĞAN; BAYINDIRLI, 2004), palmito (ROBERT et al., 1996), maçã cultivar Red Delicious (EISSA et al., 2006; RICHARD-FORGET; GOUPY; NICOLAS, 1992), purê de manga (GUERRERO-BELTRÁN; SWANSONB; BARBOSA-CÁNOVAS, 2005) e outros.

Assim, os antioxidantes têm demonstrado a sua eficiência na inibição de escurecimento. Nesse estudo, será então avaliado a incorporação dos antioxidantes na embalagem para ação no escurecimento de frutas através da liberação controlada do antioxidante para a fruta. Uma das funções da embalagem é a de preservar ao máximo a qualidade do produto, criando condições que minimizem alterações químicas, bioquímicas e microbiológicas. Porém, atualmente, o conceito tradicional de que essas funções devem ser exercidas com um mínimo de interação entre a embalagem e o produto está superado pelo desenvolvimento das embalagens ativas, uma tecnologia inovadora que permite uma maior interação da embalagem e do produto visando maior qualidade, vida útil e segurança alimentar ao consumidor (OLIVEIRA, 2002; ROONEY, 1995; SUPPAKUL et al., 2003). Um exemplo de embalagem ativa é o filme incorporado com aditivos, por exemplo os antimicrobianos e os conservantes, com o objetivo de prolongar a vida-de-prateleira dos produtos.

A liberação de aditivos por embalagens ativas aumenta a segurança do consumidor, uma vez que esses compostos ao invés de serem diretamente adicionados ao alimento, são liberados controladamente para o produto através de difusão a partir do filme. Assim, esses aditivos estão presentes em menores quantidades e mais intensamente na superfície do produto, onde a maior parte das deteriorações ocorre (GONTARD, 1997; APPENDINI; HOTCHKISS, 2002).

O objetivo desse estudo foi avaliar o efeito do uso de embalagem ativa incorporada com cisteína e sulfito na inibição do escurecimento enzimático de maçãs.

\section{Material e métodos}

\section{Material}

Foram utilizadas maçãs do cultivar Royal gala, adquiridas no mercado varejista local, bissulfito de sódio (ISOFAR-RJ) e L-cisteína (VETEC-RJ). As maçãs foram selecionadas segundo tamanho e ausência de defeitos. Os frutos foram submetidos a um pré-resfriamento em câmara fria a $4^{\circ} \mathrm{C}$ por $12 \mathrm{~h}$ 
e depois foram divididos em metades com auxílio de facas afiadas. A unidade experimental constou de quatro meias maçãs para cada tratamento a ser avaliado, nos diferentes tempos. O experimento foi feito no Laboratório de Embalagens do Departamento de Tecnologia de Alimentos, Universidade Federal de Viçosa (MG).

\section{Produção dos filmes}

Os filmes foram produzidos a base de polímero celulósico (patente requerida) pelo método "casting", sobre um filme de PVC (polivinilcloreto) esticado em uma superfície de vidro. Os agentes antiescurecimento (sulfito e cisteína) foram adicionados durante a produção do filme celulósico e a sua porcentagem foi calculada sobre o peso do polímero. Estudos preliminares foram realizados para determinação das melhores concentrações dos agentes antiescurecimento a serem incorporados nos filmes através de uma avaliação visual das maçãs envolvidas com os filmes.

Os tratamentos utilizados foram: 1- sem filme (controle), 2- filme PVC sem agente antiescurecimento (PVC), 3, 4 e 5- filme de PVC laminado com filme de celulose contendo sulfito nas concentrações de 1\% (S1), 3\% (S3) e 5\% (S5) e 6, 7 e 8 - filme de PVC laminado com filme de celulose contendo cisteína nas concentrações de 10\% (C10), $15 \%$ (C15) e $20 \%$ (C20).

As meias-maçãs foram recobertas pelos filmes, exceto no tratamento 1 , e imediatamente armazenadas em câmara fria, com controle de temperatura $\left(5 \pm 1^{\circ} \mathrm{C}\right)$ e umidade relativa $(85 \pm 3 \% \mathrm{UR})$. As amostras foram retiradas nos tempos $0,2,4$ e 6 dias após o contato das maçãs com o filme antiescurecimento.

Determinação da atividade da polifenoloxidase

A determinação da atividade enzimática foi feita segundo metodologia descrita por Simões (2004) e adaptada para maçã. Aproximadamente $4 \mathrm{~g}$ da superficie das maçãs foram picadas e homogeneizadas com 24
$\mathrm{mL}$ de tampão fosfato à $4{ }^{\circ} \mathrm{C}(0,2 \mathrm{M}) \mathrm{pH} 6,0 \mathrm{em}$ agitador (Ultra Turrax T18 basic). O homogeneizado obtido foi centrifugado por $21 \mathrm{~min}$ a $10.900 \mathrm{~g}$ a temperatura de $4{ }^{\circ} \mathrm{C}$ em centrífuga (Beckman J2 $\mathrm{MC})$. O sobrenadante resultante foi utilizado para a determinação de atividade enzimática. A uma alíquota de $30 \mu \mathrm{L}$ de extrato enzimático foi adicionado $1,3 \mathrm{~mL}$ de tampão fosfato $0,2 \mathrm{M}, \mathrm{pH} 6$ e 1,5 mL de catecol $0,2 \mathrm{M}$, homogeneizados imediatamente. Em seguida, efetuou-se a leitura de absorbância (a $425 \mathrm{~nm}$ de $5 \mathrm{em}$ $5 \mathrm{~s}$ até os primeiros $30 \mathrm{~s}$, seguido de leituras de $30 \mathrm{em}$ $30 \mathrm{~s}$, totalizando 3 minutos de reação), em espectrofotômetro (GBC UV/VIS 918). A atividade da polifenoloxidase correspondeu à inclinação da reta obtida através do gráfico Tempo (s) x Absorvância (nm).

\section{Determinação do teor de sulfito residual}

O teor residual de sulfito foi determinado pela retirada de uma fatia da superfície da maçã envolvida com o filme, totalizando $50 \mathrm{~g}$, de acordo com método quantitativo de Monier-Williams descrito nas normas do Instituto Adolfo Lutz (1985).

\section{Determinação de cor}

A determinação instrumental de cor foi avaliada através de um espectrofotômetro Colorquest XE Hunterlab, utilizando-se o iluminante padrão D65 e observador a $10^{\circ}$. O sistema de leitura utilizado foi o CIELAB, representado pelos seguintes parâmetros: coordenada $L^{*}$ (luminosidade), coordenada de cromaticidade $a^{*}$ (-a verde, +a vermelho) e a coordenada de cromaticidade $b^{*}$ (-b azul, $+\mathrm{b}$ amarelo). As amostras foram colocadas em cubeta de vidro com $10 \mathrm{~mm}$ de caminho óptico. Foi calculada a diferença total de cor $\left(\Delta \mathrm{E}^{*}\right)$ de acordo com a equação (1):

$$
\Delta \mathrm{E}^{*}=\left[\left(\Delta \mathrm{L}^{*}\right)^{2}+\left(\Delta \mathrm{a}^{*}\right)^{2}+\left(\Delta \mathrm{b}^{*}\right)^{2}\right]^{1 / 2}
$$

onde $\Delta$ é a diferença entre cada parâmetro de cor da amostra entre um tempo $\mathrm{t}$ ( 2 , $\mathrm{t} 4$ ou t6 dias) e o tempo inicial (to). 
Avaliação da inibição de escurecimento

A eficiência da inibição do escurecimento foi avaliada comparando-se os tratamentos com filme e as maçãs controle sem filme. A avaliação da porcentagem de inibição foi calculada baseada em variações do valor da absorvância a $425 \mathrm{~nm}$, de acordo com a equação (2) (EISSA et al., 2006; CRUMIÈRE, 2000):

$\%$ de inibição: $\left(\Delta \mathrm{Abs}_{\text {controle }}-\Delta \mathrm{Abs}_{\text {tratamento }}\right) * 100 / \Delta \mathrm{Abs}_{\text {controle }}$

onde $\Delta \mathrm{Abs}$ representa a diferença do valor de absorvância entre um tempo t (t2, t4 ou t6 dias) e o tempo inicial (to).

\section{Análise estatística}

$\mathrm{O}$ experimento foi conduzido em delineamento inteiramente casualizado (DIC), em parcela subdividida, com os tratamentos na parcela e o tempo na subparcela, sendo três tipos de concentração para cada tratamento (sulfito e cisteína) e quatro tempos de armazenamento, com três repetições. Foram realizadas análises de variância e de regressão a 1\% de probabilidade através do programa estatístico SAS (STATISTICAL ANALYSIS SYSTEM, 1996) System for Windows v 6.12. Para comparação entre médias foi utilizado o teste Duncan a 5\% de probabilidade. Para as análises de regressão foram ajustados modelos polinomiais de $2^{\circ}$ e $3^{\circ}$ graus. A unidade experimental constituiu-se de meia maçã.

\section{Resultados e Discussão}

Determinação da concentração dos agentes antiescurecimento

Nos testes preliminares para determinação da melhor concentração dos agentes antiescurecimento a ser incorporada nos filmes, foi verificado que sulfito em baixas concentrações (a partir de 1\%) já se mostrava eficiente na inibição do escurecimento das maçãs. Por outro lado, para cisteína foi necessária a utilização de concentrações maiores, cerca de $10 \%$.
Estudos realizados por Janovitz-Klapp et al. (1990) mostraram que, na mesma concentração, o bissulfito demonstrou maior eficiência na inibição do escurecimento em maçãs, seguido de cisteína e ácido ascórbico. Os autores atribuem isso ao fato de que o bissulfito afeta diretamente a PPO, enquanto que a cisteína reage com $o$-quinonas formando produtos que inibem de forma mais branda a reação enzimática.

\section{Inibição da polifenoloxidase}

Foi observado que a partir do quarto dia de experimento (Figura 1), todos os tratamentos apresentaram valores positivos de inibição da PPO. De acordo com Crumiére (2000), uma porcentagem de inibição entre 0 e $100 \%$ indica que o tratamento foi efetivo como inibidor do escurecimento. Valores maiores que $100 \%$ indicam a ocorrência de branqueamento da amostra pelo tratamento, enquanto valores negativos indicam que o tratamento promoveu escurecimento preferencialmente que inibição.

No tempo 6, as três concentrações de sulfito não diferiram entre si pelo teste de Duncan a 5\% de probabilidade. Para a cisteína, a maior inibição ocorreu para o tratamento C20 (Figura 1). As maçãs envolvidas com PVC apresentaram efeito inibitório significativamente $(\mathrm{p}<0,05)$ semelhante às amostras envolvidas em filme com sulfito (S1 e S5) e cisteína (C20). O filme de PVC apesar de não possuir boa barreira a gases, como o oxigênio (ROBERTSON, 1993), ainda assim contribuiu para a redução da atividade enzimática, provavelmente por dificultar o contato do sitio ativo da enzima com o oxigênio, o que mostra que esse plástico pode exercer um efeito complementar na inibição do escurecimento enzimático.

De acordo com Özolu e Bayindirli (2002), a cisteína não possui efeito inibitório direto sobre a PPO. Durante a oxidação, ela reage com as $O$ quinonas formando complexos conjugados cisteinaquinona, que não são substratos para a enzima, mas possuem propriedades de inibição competitiva com uma afinidade maior pela enzima do que os seus 
precursores. Quando a concentração de cisteína é maior que a de fenóis, estes são impedidos de agir sobre a enzima, sem escurecimento. Ao contrário, quando a concentração de cisteína é baixa, as o-quinonas são formadas em excesso e prejudicam a formação desses complexos conjugados, permitindo a regeneração dos fenóis e a formação de pigmentos escuros.
A

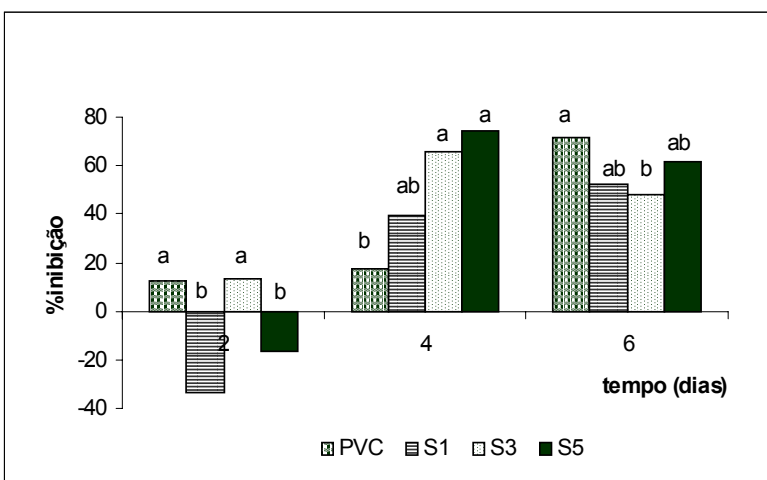

B

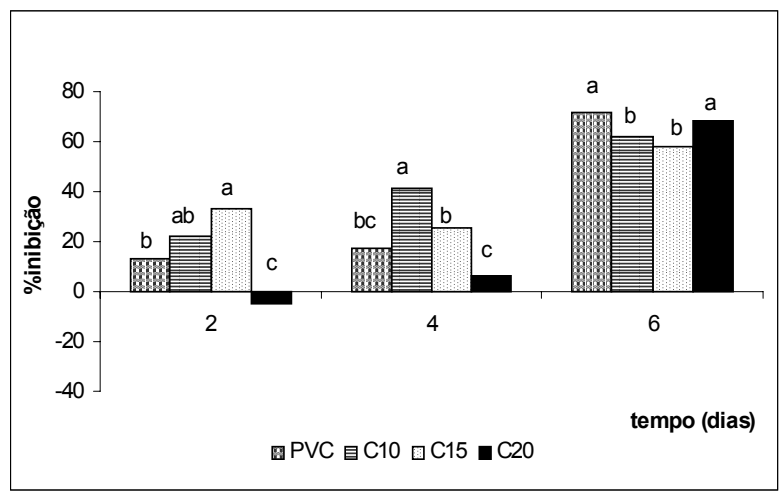

*médias seguidas de uma mesma letra não diferem entre si pelo teste de Duncan a $5 \%$ de probabilidade

Figura 1. Porcentagem de inibição da PPO em maçãs envolvidas com filme incorporado com sulfito (A) e com cisteína (B).

A porcentagem de inibição do sulfito e da cisteína apresentou variação ao longo do tempo. De acordo com Robert et al. (1996), dois modelos podem explicar as curvas de inativação enzimática. Um deles seria a existência de duas isoenzimas que se comportam de forma diferente quando submetidas a um tratamento de inativação e possuem duas constantes de reação. Outro seria a existência de duas etapas para a inativação da enzima que passa por uma forma de ação intermediária entre o seu estado nativo e inativo. Roux et al. (2003) sugerem um modelo de inibição que é composto por algumas constantes de reação e que diferentes substratos para a enzima e seus produtos de degradação combinados com o agente antiescurecimento são capazes de produzir diferentes tipos de mecanismos de inibição de acordo com a fonte de PPO. Isso pode explicar as variações da porcentagem de inibição encontradas nesse estudo durante o período de estocagem.

A maçã contém algumas classes de fenóis, como hidroxicinâmicos, flavan-3-ol, ácido clorogênico, epicatequina e procianidina, e a relativa proporção entre elas é importante para a coloração final dos tecidos. A PPO possui diferente especificidade para esses substratos, o que implica em produtos resultantes do escurecimento com intensidade de cor variável durante as fases da reação. Geralmente as o-quinonas são menos estáveis e menos escuras e na segunda fase da reação os produtos podem ser mais escuros (GOUPY et al., 1995).

Resultados de pesquisas obtidos por Eissa et al. (2006) e Crumiére (2000) para cisteína e sulfito, respectivamente, mostraram um aumento no efeito inibidor sobre a PPO à medida que a concentração dos agentes foi aumentada. Robert et al. (1996) também demonstraram que a atividade da PPO em palmito reduziu com o aumento da concentração de L-cisteína. Porém, esses estudos foram realizados com o agente sendo adicionado diretamente ao produto, diferindo do presente estudo no qual os agentes foram incorporados à embalagem. Neste sistema, a taxa de liberação dos agentes antiescurecimento pela embalagem é dependente do tempo, o que pode resultar em variações na porcentagem de inibição durante a estocagem.

Em um estudo sobre a PPO em maçãs cv. Gala, Sataque e Wosiacki (1987) mostraram que essa 
enzima está localizada em toda a região da polpa da maçã, porém de maneira não uniforme. De acordo com os autores, a ação mais intensa da PPO encontra-se próxima à epiderme, na parte central e ao redor dos feixes vasculares. Assim, pode-se atribuir algumas variações na determinação da inibição devido à falta de homogeneidade na distribuição da PPO, apesar de que foi tomado o cuidado de retirar uma amostra bem representativa da superfície da maçã. Também, de acordo com Valderrama, Marangoni e Clemente (2001), as maçãs do cultivar Gala possuem baixos teores de PPO tanto na casca quanto na polpa, quando comparadas com o cultivar Fuji.

Como o estudo foi realizado à temperatura de refrigeração $\left(4^{\circ} \mathrm{C}\right)$, a enzima não apresentava sua atividade ótima, que se situa entre $30^{\circ}$ e $40^{\circ} \mathrm{C}$, de acordo com Sataque e Wosiacki (1987). Esses autores reportam que a atividade da PPO diminuiu de $89 \%$ a $20^{\circ} \mathrm{C}$ para $37 \%$ a $10^{\circ} \mathrm{C}$. Porém, foi observado que mesmo abaixo de $4^{\circ} \mathrm{C}$, a enzima ainda exibia atividade, indicando que a reação de escurecimento não poderia ser eliminada completamente somente por estocagem a baixa temperatura.

\section{Análise de cor}

A análise de variância mostrou diferença significativa $(p<0.01)$ entre todos os parâmetros de cor $\left(\mathrm{L}^{*}, \mathrm{a}^{*}\right.$ e $\left.\mathrm{b}^{*}\right)$. Os valores de $\mathrm{L}^{*}$, que indica a luminosidade da amostra na faixa de 100 (branco) a 0 (negro), mostram que os filmes tanto com sulfito quanto com cisteína, comparados com o filme controle, proporcionaram maior brilho às maçãs (Figura 2). O tratamento S5 foi mais satisfatório devido à tendência de aumento de luminosidade a partir do $3^{\circ}$ dia. Essa tendência também foi observada para os tratamentos C15 e C20. Porém, para $\mathrm{C} 20$, o comportamento da curva foi diferente dos demais, representada por um modelo de $3^{\circ}$ grau e, no final do experimento, pôde-se observar que as maçãs apresentaram-se mais claras do que no início. Isso pode ser devido a uma reação de oxidação dos pigmentos da maçã pela cisteína em alta concentração. Estudos de Ding et al. (2002) mostraram que a cisteína em concentrações mais elevadas pode oxidar o ácido clorogênico, um substrato da PPO presente em maçãs, após uma hora de incubação. Nesse caso, a cisteína não influencia a atividade da enzima, apesar de inibir a formação de coloração escura, o que foi observado visualmente para o tratamento $\mathrm{C} 20$.

As variações dos valores de $L^{*}$, observadas em vários tratamentos, podem ser devido ao comportamento da enzima, que geralmente é inativada em dois estágios, como explicado anteriormente. Também, como a reação de escurecimento é um sistema dinâmico que contém vários produtos derivados, mais ou menos estáveis, podem ocorrer variações na velocidade da reação, o que resulta na alteração de cor (BILLAUD et al., 2003). Em um estudo de nove cultivares de maçãs, Goupy et al. (1995) observaram que os valores de $\mathrm{L} *$ diminuíram de 98 para 90 em soluções modelo contendo ácido clorogênico e epicatequina que foram oxidados por PPO.

Para a estimação de escurecimento, o valor L* tem sido considerado como o melhor parâmetro de cor; geralmente pequenas variações têm sido observadas nos valores de $a^{*}$ e b* (IYIDOĞAN; BAYINDIRLI, 2004). No presente estudo o decréscimo mais acentuado do valor de $L^{*}$ foi observado para os tratamentos controle e PVC.

A coordenada $a^{*}$, que indica a variação de verde $\left(-a^{*}\right)$ a vermelho $\left(+a^{*}\right)$, é um parâmetro importante para o estudo de escurecimento, pois a cor marrom resultante da presença de melaninas representa uma combinação do verde e vermelho. Um maior escurecimento é representado por um tom mais avermelhado, ou seja, maior valor de a*. Os tratamentos foram satisfatórios nesse aspecto, pois reduziram o valor de a* quando comparado com os tratamentos controle. O tratamento com filme de PVC mostrou-se eficiente na redução do valor a*, porém o uso dos agentes incorporados ao filme reduziu com maior intensidade os valores de a* (Figura 3). 
A

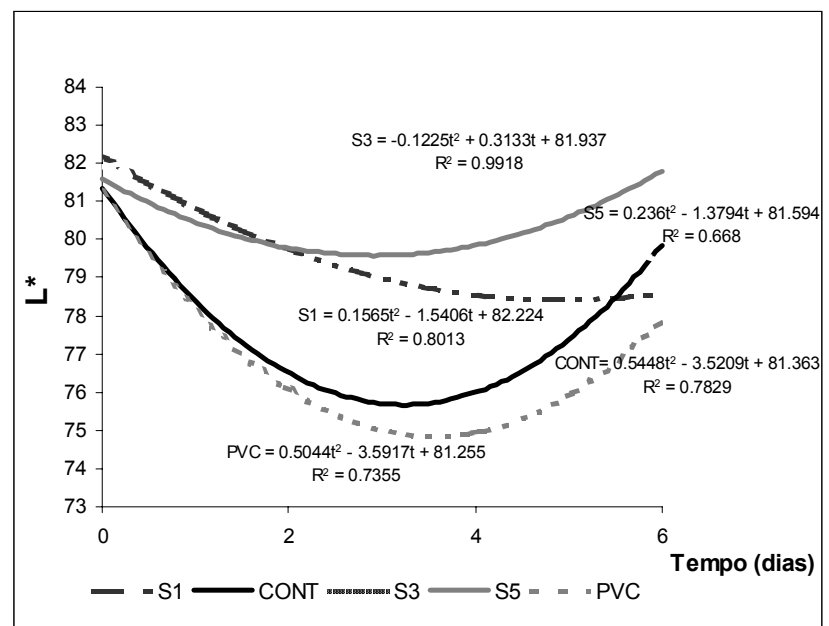

B

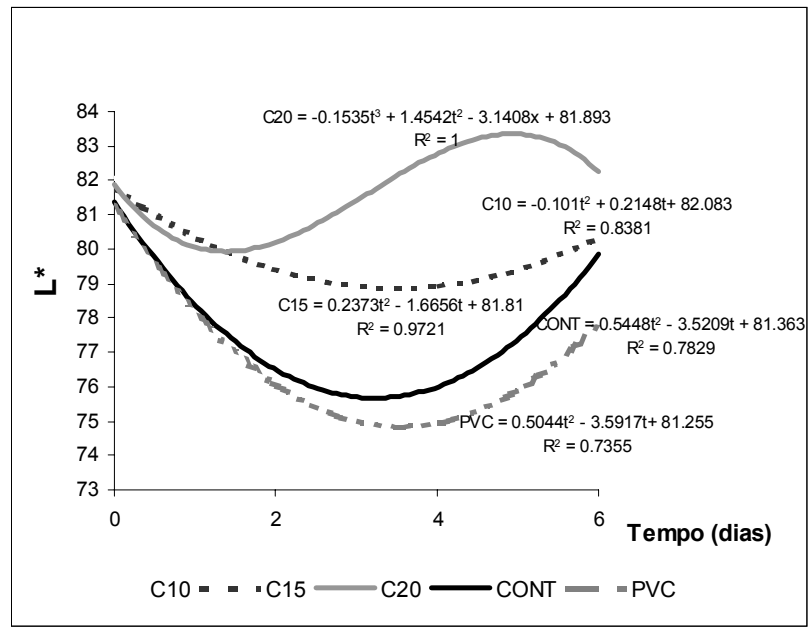

Figura 2. Porcentagem de cor L para maçãs envolvidas com filmes incorporados com diferentes concentrações de sulfito (A) e cisteína (B).

A

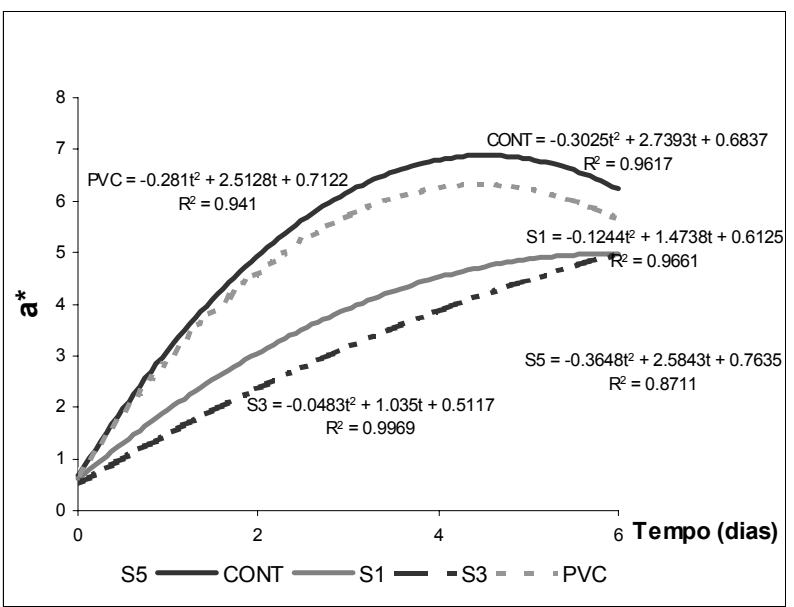

B

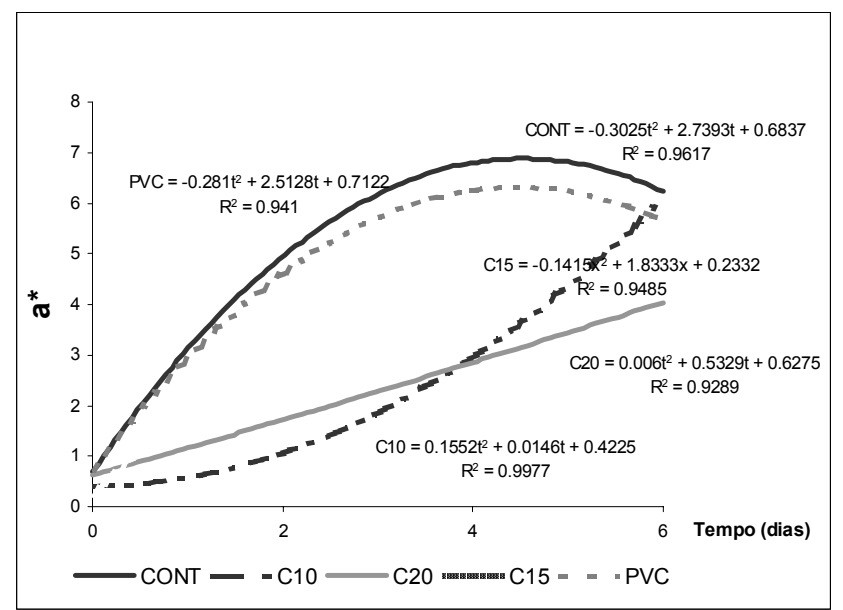

Figura 3. Porcentagem de cor $\mathrm{a}^{*}$ para maçãs envolvidas com filmes incorporados com diferentes concentrações de sulfito (A) e cisteína (B).

A coordenada $b^{*}$, relacionada ao eixo que varia de azul (-b*) a amarelo ( $\left.+b^{*}\right)$, não demonstrou grandes variações entre os tratamentos, situando-se na faixa positiva e tendendo para o amarelo, cor característica da maçã (Figura 4).

O parâmetro diferença de cor também é usado para se verificar modificações na cor causadas pelo escurecimento. Como pode ser observado na Figura 5 , houve uma tendência no aumento de $\Delta \mathrm{E}^{*}$ ao longo do tempo de estocagem, indicando escurecimento das amostras. Entretanto, os tratamentos controles (PVC e CONT) apresentaram os maiores valores para $\Delta \mathrm{E}^{*}$ mostrando que os demais tratamentos foram satisfatórios, pois reduziram a diferença de cor entre os tempos. Novamente observa-se que os tratamentos C20 e S5 apresentaram melhores resultados para diferença de cor, ou seja, menores valores de $\Delta \mathrm{E}^{*}$ ao final do experimento, em relação aos demais tratamentos. 
A

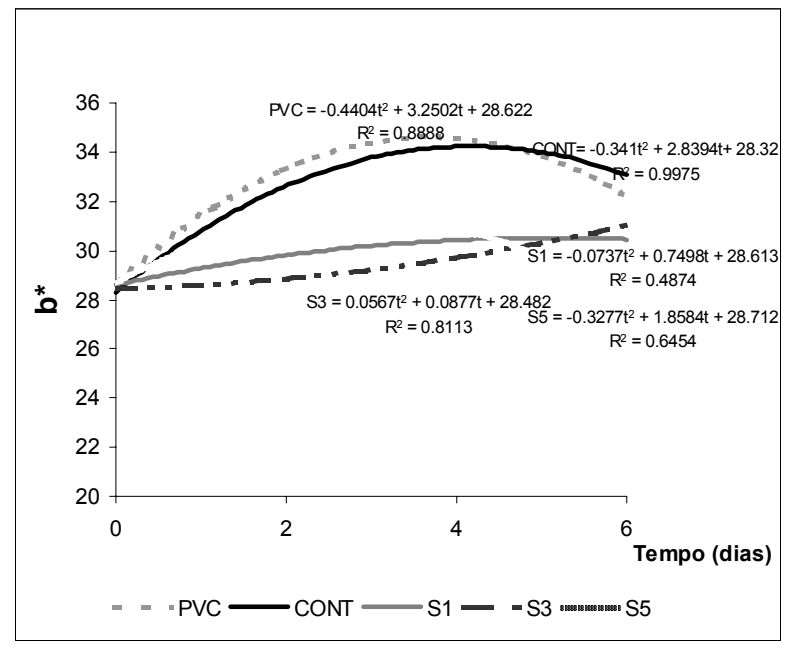

B

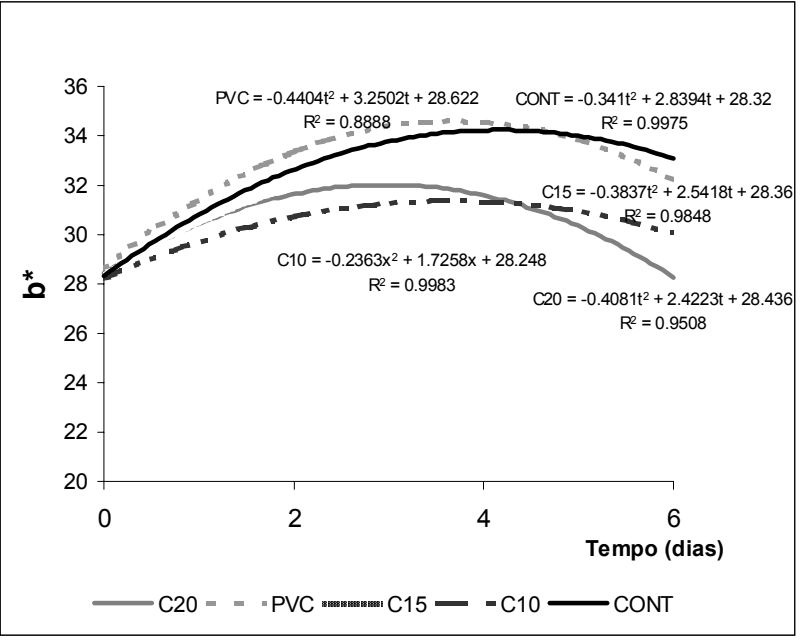

Figura 4. Porcentagem de cor $b^{*}$ para maçãs envolvidas com filmes incorporados com diferentes concentrações de sulfito (A) e cisteína (B).

A

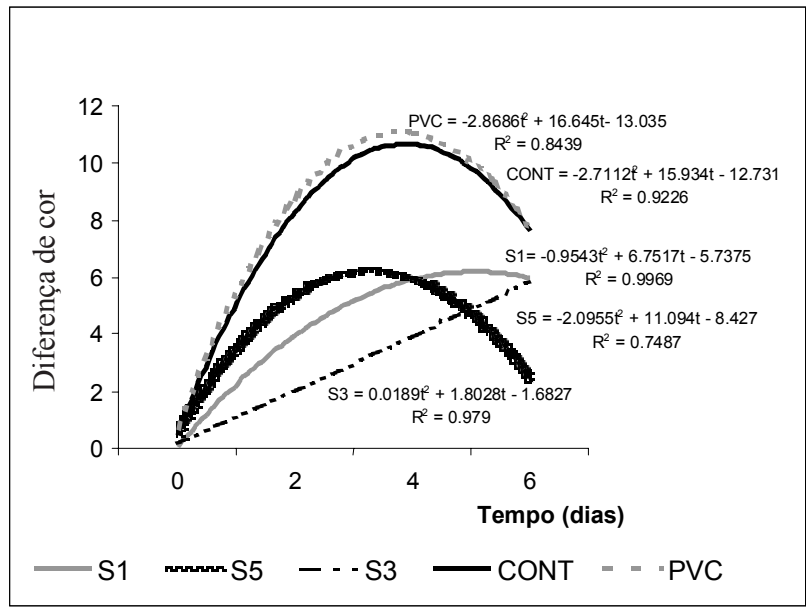

B

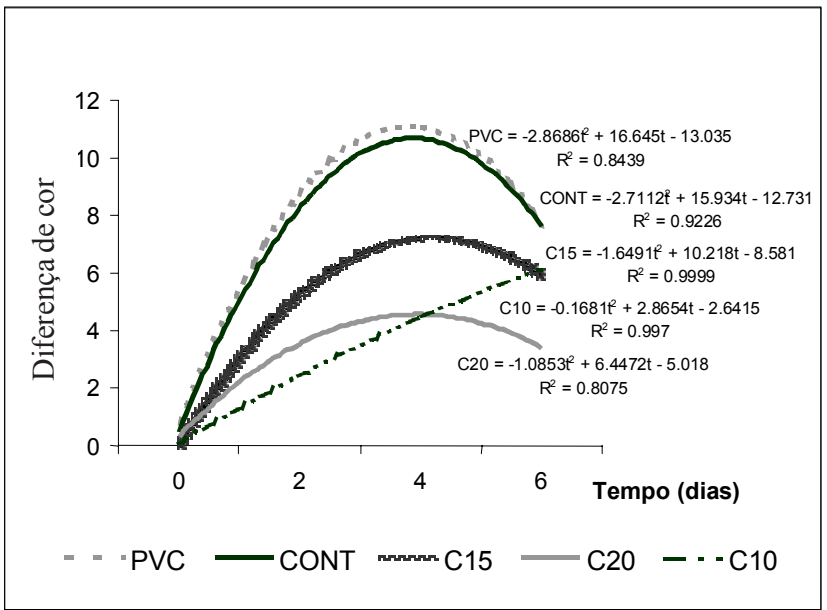

Figura 5. Valores de $\Delta \mathrm{E}^{*}$ para maçãs envolvidas com filmes incorporados com diferentes concentrações de sulfito (A) e cisteína (B).

Todos os tratamentos apresentaram menor escurecimento quando comparados ao controle e PVC (Figura 6). Além disso, a maçã controle resultou desidratada, mostrando que os filmes inibiram a perda de água do produto durante a estocagem sob refrigeração.

No tratamento $\mathrm{C} 20$, principalmente em $\mathrm{t} 2$, foi observado uma despigmentação da maçã, já discutido anteriormente. Quando existe uma concentração de cisteína em excesso, ocorre uma proteção permanente contra o escurecimento enzimático, porém isso geralmente prejudica o produto em termos de características organolépticas (RICHARDFORGET; GOUPY; NICOLAS, 1992) e causa um efeito de branqueamento (ÖZOĞLU; BAYINDIRLI, 2002). No tempo 6, as maçãs envolvidas com filme $\mathrm{C} 10$ iniciaram o escurecimento. Assim, o tratamento C15 se mostrou o mais eficiente.

Em relação ao sulfito todos os tratamentos se mostraram eficientes, sem escurecimento expressivo das maçãs em todos os tempos. O tratamento somente com PVC não foi capaz de prevenir o escurecimento da maçã (Figura 6). 


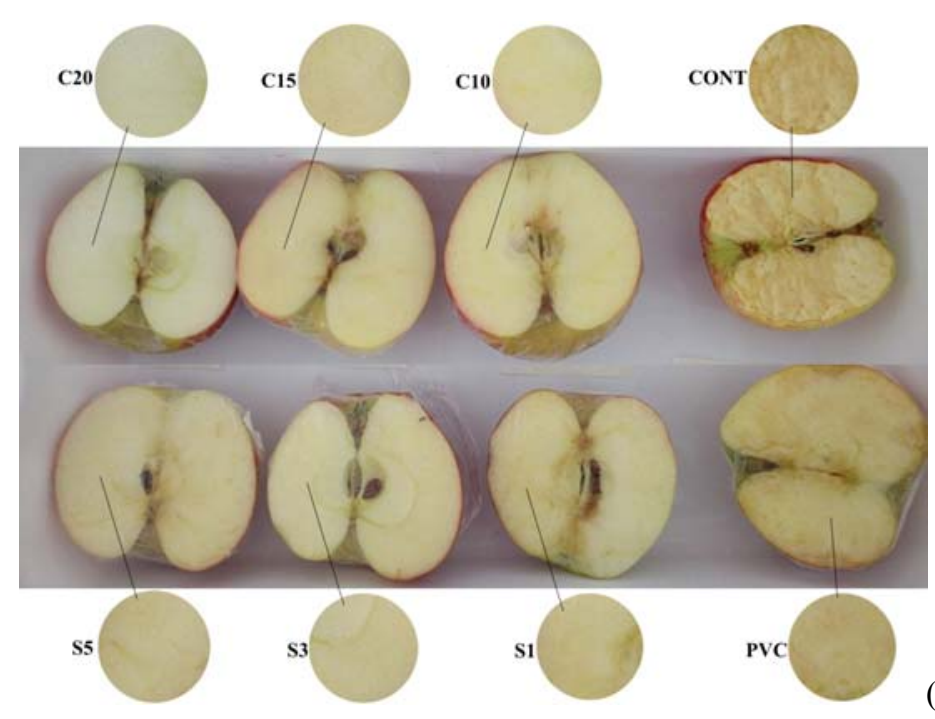

(a)

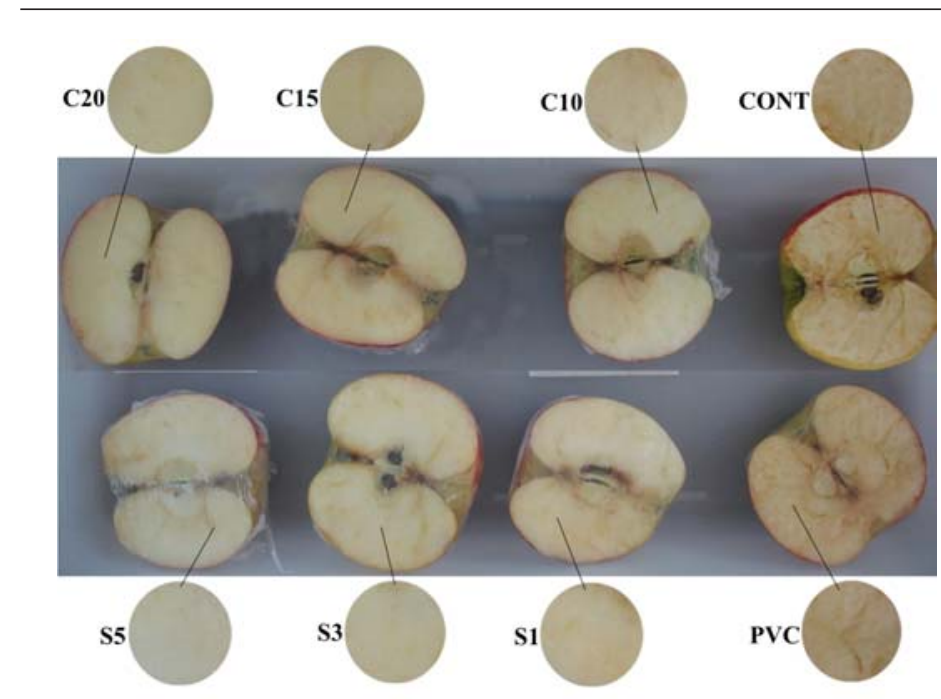

(b)

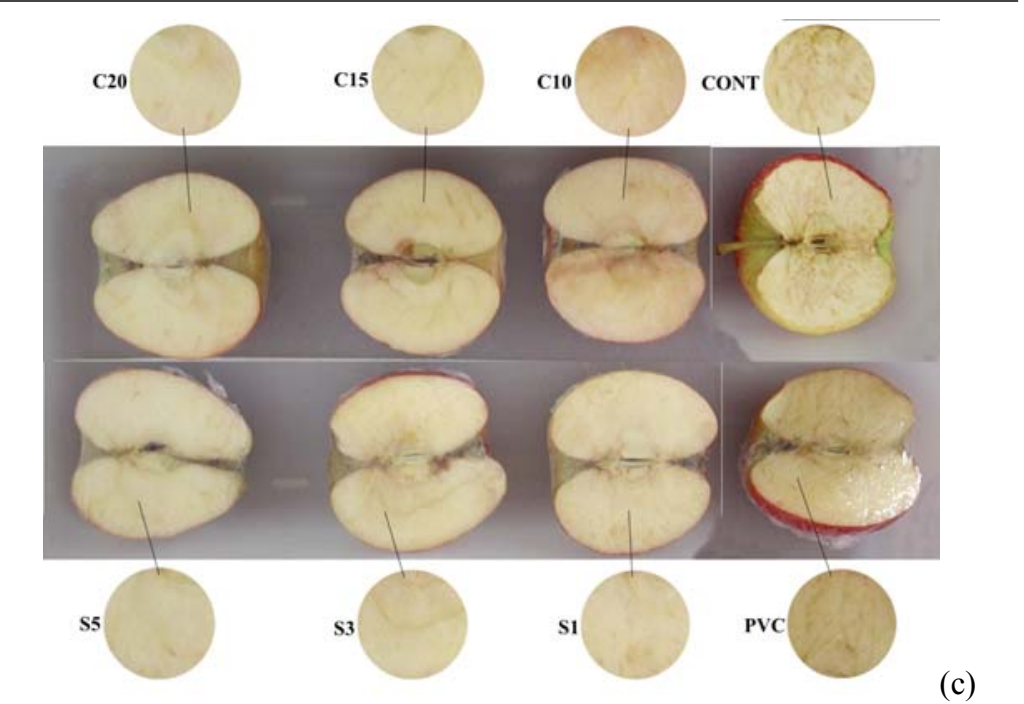

Figura 6. Fotos das maçãs após 2 dias (a), 4 dias (b) e 6 dias (c) de contato com filmes contendo 20\% (C20), 15\% (C15), 10\% (C10) de cisteína; $1 \%$ (S1), 3\% (S3), 5\% (S5) de sulfito; controle sem filme (CONT) e sem agente antiescurecimento (PVC). 
Teor de sulfito residual

Não foi detectado sulfito nas amostras pela metodologia utilizada até o $4^{\circ}$ dia de estocagem e, no $6^{\circ}$ dia no tratamento $\mathrm{S} 5$, observou-se uma migração de $0,015 \mathrm{~g} \mathrm{SO}_{2} / 100 \mathrm{~g}$, abaixo do valor permitido pela legislação de $0,03 \mathrm{~g} \mathrm{SO}_{2} / 100 \mathrm{~g}$ de produto (BRASIL, 2005). Esses valores se mostram bastante satisfatórios, uma vez que o sulfito em excesso pode causar problemas à saúde dos consumidores (VICENT, 2007; SOARES; CAVALHEIRO, 2001) e demonstram a vantagem da embalagem ativa que permitiu controle do escurecimento com uma migração do sulfito em nível duas vezes menor que o permitido pela legislação. Os outros compostos não foram determinados, pois não existem limites máximos na legislação.

\section{Conclusões}

De acordo com os resultados apresentados acima se conclui que:

Baixas concentrações de sulfito (1\%) mostraramse eficientes na inibição do escurecimento das maçãs e altas concentrações de cisteína (15\%) foram necessárias para a obtenção do mesmo resultado. Os valores de $\mathrm{L}^{*}$ mostraram que os tratamentos tanto com sulfito quanto com cisteína, comparados com os tratamentos controle, proporcionaram maior brilho às maçãs e que os tratamentos S5 e C15, apresentaram-se mais satisfatórios devido à tendência de aumento de luminosidade. Os valores de a* mostraram que os tratamentos foram satisfatórios para manutenção da cor e em relação à coordenada $b^{*}$, não houve grandes variações entre os tratamentos. Para a diferença de cor entre os tempos $\left(\Delta \mathrm{E}^{*}\right)$ houve uma tendência de aumento ao longo do tempo de estocagem, indicando escurecimento das amostras, mas os tratamentos foram satisfatórios em relação ao controle. $O$ teor de sulfito liberado para a maçã foi menor que o permitido pela legislação, diminuindo assim, os níveis de aditivos que serão ingeridos pelo consumidor. Comprovou-se a eficiência das embalagens ativas que proporcionaram conservação do produto, inibindo o desenvolvimento de escurecimento. Esse tipo de embalagem representa uma futura aplicação de filmes a serem usados no recobrimento de maçãs cortadas ou fatiadas, e provavelmente outras frutas e vegetais, a serem guardadas em geladeira.

\section{Agradecimentos}

Os autores agradecem o apoio financeiro do CNPq, CAPES, FINEP e FAPEMIG.

\section{Referências}

APPENDINI, P.; HOTCHKISS, J. H. Review of antimicrobial food packaging. Innovative Food Science and Emerging Technologies, Amsterdam, The Netherlands, v.3, n.2, p.113-126, 2002.

ARAÚJO, J. M. A. Química de alimentos: teoria e prática. 2.ed. Viçosa: Editora da UFV, 2001.

BILLAUD, C.; ROUX, E.; BRUN-MÉRIMEE, S.; MARASCHIN, C.; NICOLAS, J. Inhibitory effect of unheated and heated d-glucose, d-fructose and l-cysteine solutions and Maillard reaction product model systems on polyphenoloxidase from apple. I. Enzymatic browning and enzyme activity inhibition using spectrophotometric and polarographic methods. Food Chemistry, London, v.81, n.1, p.35-50, 2003.

BRASIL. Agência Nacional de Vigilância Sanitária ANVISA. Resolução nº . 217, de 29 de julho de 2005. Dispõe sobre a aprovação da extensão de uso do aditivo dióxido de enxofre e seus sais de cálcio, sódio e potássio. Diário Oficial [da] República Federativa do Brasil, Brasília, 01 agosto de 2005.

CRUMIÉRE, F. Inhibition of enzymatic browning in food products using bio-ingredients. 2000. Thesis (Master of Science) - Department of Food Science and Agricultural Chemistry, McGill University, Montreal.

DING, C. K.; CHACHIN, K.; UEDA, Y.; WANG, C. Y. Inhibition of loquat enzymatic browning by sulfhydryl compounds. Food Chemistry, London, v.76, n.2, p.213$218,2002$.

EISSA, H. A.; FADEL, H. H. M.; IBRAHIM, G. E.; HASSAN, I. M.; ELRASHID, A. A. Thiol containing compounds as controlling agents of enzymatic browning in some apple products. Food Research International, Ottawa, v.39, n.8, p.855-863, 2006. 
FRIEDMAN, M. Food browning and its prevention: an overview. Journal of Agricultural and Food Chemistry, Easton, v.44, n.3, p.631-653, 1996.

GARCIA, E.; BARRETT, D. M. Preservative treatments for fresh-cut fruits and vegetables. In: LAMIKANRA, O. (Ed.). Fresh cut fruits and vegetables: Science, Technology and Market. USA: CRC Press, 2002.p.268-297.

GONTARD, N. Active packaging. In: SOBRAL, P. J. A.; CHUZEL, G., (Ed.). Workshop sobre polímeros. Pirassununga: FZEA, 1997. p.23-27.

GOUPY, P.; AMIOT, M. J.; RICHARD-FORGET, F.; DUPRAT, F., AUBERT, S.; NICOLAS, J. Enzymatic browning of model solutions and apple phenolic extracts by apple polyphenoloxidase. Journal of Food Science, Chicago, v.60, n.3, p.497-501, 1995.

GUERRERO-BELTRÁN, J. A.; SWANSONB, B. G.; BARBOSA-CÁNOVAS, G. V. Inhibition of polyphenoloxidase in mango puree with 4-hexylresorcinol, cysteine and ascorbic acid. Lebensmittel wissenschaft und technologie, London, v.38, n.6, p.625-630, 2005.

INSTITUTO ADOLFO LUTZ. Normas analíticas do Instituto Adolfo Lutz: métodos químicos e físicos para análises de alimentos. 3.ed. n.45, São Paulo: IAL, 1985. v.1.

IYIDOĞAN, N. F.; BAYINDIRLI, A. Effect of L-cysteine, kojic acid and 4-hexylresorcinol combination on inhibition of enzymatic browning in Amasya apple juice. Journal of Food Science, Chicago, v.62, n.3, p.299-304, 2004.

JANOVITZ-KLAPP, A. H.; RICHARD, F. C.; GOUPY, P. M.; NICOLAS, J. J. Inhibition studies on apple polyphenol oxidase. Journal of Agricultural and Food Chemistry, Easton, v.38, n.4, p.926-931, 1990.

LOZANO-DE-GONZALEZ, P. G.; BARRETT, D. M.; WROLSTAD, R. E.; DURST, R. W. Enzymatic browning inhibited in fresh and dried apple rings by pineapple juice. Journal of Food Science, Chicago, v.58, n.2, p.399-404, 1993.

MARSHALL, M. R.; KIM, J.; WEI, C. I. Enzymatic browning in fruits, vegetables and seafoods. 2000. Disponível em: <http://www.fao.org/ag/Ags/agsi/ ENZYMEFINAL/Enzymatic\%20Browning.html>. Acesso em: 16 jan. 2007.

MARTINEZ, M. V.; WHITAKER, J. R. The biochemistry and control of enzymatic browning. Trends in Food Science \& Technology, Cambridge, v.6, n.6, p.195-200, 1995.

OLIVEIRA, L. M. Filmes plásticos incorporados de agentes antimicrobianos. Informativo do Centro de Tecnologia de Embalagens, São Paulo, v.14, n.2, p.4-7, 2002.

ÖZOĞLU, H.; BAYINDIRLI, A. Inhibition of enzymic browning in cloudy apple juice with selected antibrowning agents. Food Control., Guildford, v.13, n.4-5, p.213-221, 2002.

RICHARD-FORGET, F. C.; GOUPY, P. M.; NICOLAS, J. J. Cysteine as an inhibitor of enzymatic browning. 2. Kinetic
Studies. Journal of Agricultural and Food Chemistry, Easton, v.40, n.11, p.2108-2113, 1992.

ROBERT, C.; RICHARD-FORGET, F.; ROUCH, C.; PABION, M.; CADET F. A Kinetic study of the inhibition of palmito polyphenol oxidase by L-cysteine. The International Journal of Biochemistry \& Cell Biology, Pergamon, v.28, n.4, p.457-463, 1996.

ROBERTSON, G. L. Food packaging: principles and practice. New York: Marcel Dekker, 1993.

ROCHA, A. M. C. N.; MORAIS, A. M. M. B. Characterization of polyphenoloxidase (PPO) extracted from "Jonagored" apple. Food Control, Guildford, v.12, n.2, p.85-90, 2001.

ROONEY, M. L. Active packaging in polymer films. In: ROONEY, M.L. (Ed.). Active food packaging. London: Blakie Academic and Professional, 1995. p.74-110.

ROUX, E.; BILLAUD, C.; MARASCHIN, C.; BRUNMÉRIMEE, S.; NICOLAS, J. Inhibitory effect of unheated and heated d-glucose, d-fructose and l-cysteine solutions and Maillard reaction product model systems on polyphenoloxidase from apple. 2 . Kinetic study and mechanism of inhibition. Food Chemistry, London, v.81, n.1, p.51-60, 2003.

SAS INSTITUTE. The SAS-system for windows: statistical analysis system, release 6.12 (software). Cary: SAS Institute, 1989-1996.

SATAQUE, E. Y.; WOSIACKI, G. Caracterização da polifenoloxidase da maça (Malus domestica, var. Gala). Arquivos de Biologia e Tecnologia, Curitiba, v.30, n.2, p.287-299, 1987.

SIMÕES, A. N. Alterações químicas e atividades de enzimas em folhas de couve inteiras e minimamente processadas. 2004. Dissertação (Mestrado em Fisiologia Vegetal) - Universidade Federal de Viçosa, Viçosa.

SOARES, M. H. F. B.; CAVALHEIRO, E. T. G.. Pigmentos naturais: a química das cores na natureza.. Revista Expressão, Guaxupé, v.2, n.2, p 249-259, 2001.

SUPPAKUL, P.; MILTZ, J.; SONNEVELD, K.; BIGGER, S. W. Active packaging technologies with an emphasis on antimicrobial packaging and its applications. Journal of Food Science, Chicago, v.68, n.2, p.408-420, 2003.

VALDERRAMA, P.; MARANGONI, F.; CLEMENTE, E. Efeito do tratamento térmico sobre a atividade de peroxidase (POD) e polifenoloxidase (PPO) em maçã (Mallus comunis). Ciência e Tecnologia de Alimentos, Campinas, v.21, n.3, 2001.

VICENT, R. Apostila conservação de alimentos: química industrial de alimentos. UNIJUÍ. Disponível em: < http:// www.sinpro-rs.org.br/paginasPessoais/layout $2 /$ down.asp?id=394>. Acesso em: 14 jan. 2007. 